\title{
Predicting Tunnel Squeezing: A Discussion based on Two Tunnel Projects
}

\section{Krishna Kanta Panthi}

Abstract: Tunnel squeezing is a phenomenon, which is frequently confronted while tunneling through Himalayan rock mass. Weak and schistose rocks like mudstone, shale, slate, phyllite, schist, highly schistose mica gneiss and the rock mass of the tectonic fault zones are incapable of sustaining high stresses. A reliable and trustworthy prediction on the extent of squeezing is therefore essential. The reliable prediction results help to make strategy regarding stabilizing measures and optimization of tunnel rock support well in advance.

This paper is mainly focused in analyzing the tunnel squeezing that took place in connection with the two tunnel cases; i.e. Kali Gandaki 'A' and Middle Marsyangdi headrace tunnels. The main focus is given to look on the applicability of squeezing analysis using Hoek and Marinos approach in combination with the equation proposed by Panthi for the estimation of rock mass strength for highly schistose rocks of the Himalaya. The measured tunnel convergence (squeezing) and lab tested mechanical properties of the rocks from these two headrace tunnels have been used to verify the applicability of the proposed methods and also the uncertainty analysis approach on squeezing introduced by Panthi.

Key words: Tunnel squeezing, Kali Gandaki 'A' headrace tunnel, Middle Marsyangdi headrace tunnel, Nepal

\section{Introduction}

A fter the excavation is made, re-distribution $A$ of rock stresses occurs on the periphery of the tunnel contour. This re-distribution of stress leads to overloading in the rock mass surrounding a tunnel periphery, which results in deformation in the tunnel wall/periphery. If the rock mass strength is less than the induced (redistributed) magnitude of stresses, a failure in the rock mass occurs. The type of failure and extent of stress build up, however, depend on the type of rocks. There are mainly two forms of instability caused by induced stresses; i.e. rock burst/rock spalling in strong rock or tunnel squeezing (plastic deformation) in weak rock. It is noted here that the weak and highly schistose rock mass behave very differently from the isotropic, stronger and brittle rock mass when subjected to induced tangential stresses along the tunnel periphery.

The high degree of schistosity present in therock mass, more precisely, the extent of thin foliation is the dominating characteristic that leads to the formation of a viscoplastic zone of micro-fractured rock mass deep into the tunnel wall as shown in Figure 1. This leads to a time dependent inward movement of rock material and the applied support experiences a gradual build up of pressure. This time-dependent inward movement (plastic deformation) of the rock material towards the tunnel when subjected to tangential stress is defined as

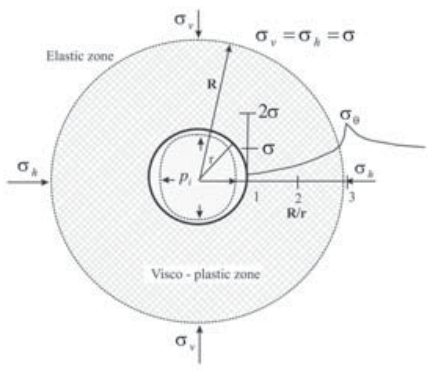

Figure 1. An Illustration of Plastic Deformation (Squeezing) in a Circular Tunnel (Panthi 2006; Panthi 2012). tunnel squeezing (Panthi 2012).

The rock masses of the tectonically active Himalaya are highly directional concerning strength and deformability. Being highly schistose and weaker in their mechanical characteristics, the rocks such as slate, phyllite, phyllitic schist, schists, micagneiss and rock mass of the tectonic fault zones of the Himalaya lack sufficient bonding (confinement), and hence have considerably reduced self-supporting capability (Panthi 2006). Therefore, the main area of concern regarding tunnel stability in many oc-casions is related to tunnel squeezing (large plastic deformation).

The best way to deal with squeezing is to be able to predict and estimate the extent of squeezing so that a fairly good strategy can be made well in advance regarding stabilizing measures. Such effort helps to minimize stability problems and also helps to optimize tunnel rock support (2012). This means, predicting squeezing reliably is the key issue. Panthi (2006) has established an uncertainty analysis procedure for analyzing squeezing. The method focuses on the effect of variation on each input parameter and concludes that it is the most reliable way of predicting the extent of tunnel squeezing (Panthi and Nilsen 2010). The author used instrumented data from the Kali Gandaki 'A' headrace tunnel and lab tested strength and deformability charac-teristics for both Kali Gandaki ' $\mathrm{A}$ ' and Middle Marsyangdi projects. The author also predicted tunnel squeezing along the headrace tunnel segment of the Middle Marsyangdi, which was under construction at that time (Panthi and Nilsen 2010).

The construction of the Middle Marsyangdi tunnel is now completed and instrumented tunnel convergence data are available. Therefore, the main aim of this paper is to check the accuracy of the prediction model and the equation proposed by the author (Panthi 2006) for estimating rock mass strength (Equation 3) and enhancing the applicability of tunnel squeezing prediction. 


\section{Kali Gandaki 'A' Headrace Tunnel}

The Kali Gandaki 'A' Hydroelectric Project has an installed capacity of 144 MW. To produce energy, the project utilizes a 45 kilometer long loop of the relatively flat bedded Kali Gandaki river in a shortcut by diverting the water through a 5,950 metes long headrace tunnel. The tunnel has approximately 60 square meters of excavation crosssection and is a medium head scheme (net head 115 meters) with a rated design discharge of $141 \mathrm{~m}^{3} / \mathrm{s}$.

Geologically, the project area lies in the lesser Himalayan highly deformed rock formations and is relatively close to the Main Boundary Thrust (MBT). The rocks in the project area are mainly comprised of Precambrian to lower Paleozoic shallow marine sediments. As shown in Figure 2, the headrace tunnel passes through highly deformed siliceous and graphitic phyllite that varies in mineral composition and degree of metamorphism. As the Himalayan region is still active in tectonic movement, the rock mass in the project has been also subjected to shearing, folding and faulting. The phyllite is of poor quality, thinly foliated and highly sheared (NEA 2002). The orientations and dips of the joints sets are scattered due to extreme folding and shearing giving no distinct joint system except for foliation joints.

As shown in Figure 2, the maximum rock cover above the tunnel reaches to approximately 620 meters,

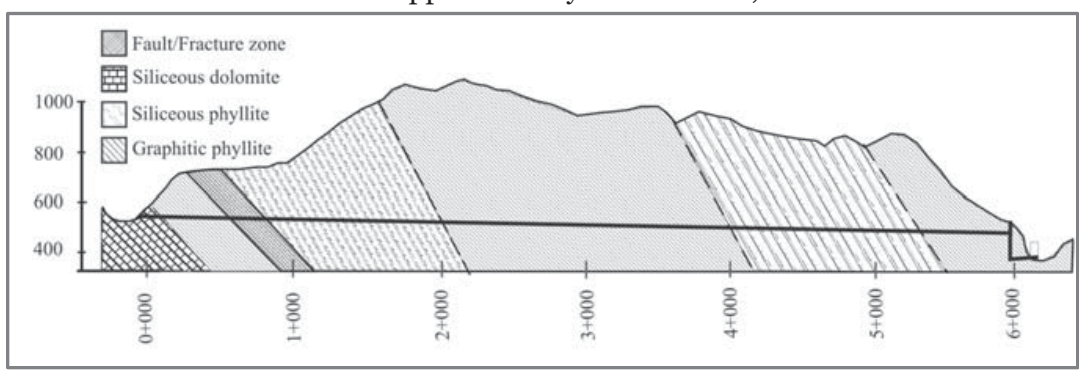

Figure 2. Longitudional Profile of the Kali Gandaki 'A' Headrace Tunnel.
The project consists of a 5300 meter long headrace tunnel (Figure 3) and has a 6.4 meter excavation diameter (NEA 1998).

Geologically, this project also lies in the lesser Himalayan meta-sedimentary rock formations. As shown in Figure 3, the main rock types in the project area are quartzite, phyllite and meta-sandstone with intercalation features. The upstream short section of the headrace tunnel is located in highly to medium weathered, fractured and foliated quartzite of fair to good quality. The remaining downstream section is mostly passing through thinly foliated micaceous and siliceous phyllite. The phyllite of the area is intercalated with bands of quartzite and meta-sandstone. The micaceous phyllite is highly sheared, micro-folded and deformed, and is of extremely poor quality, whereas the siliceous phyllite is fractured (Panthi 2006) and (Panthi and Nilsen 2007). The maximum rock cover above the tunnel reaches approximately 450 meters, and more than 95 percent of the tunnel alignment has overburden (rock cover) exceeding 100 meters.

\section{Squeezing Prediction}

The Hoek and Marinos (2000) approach for predicting tunnel squeezing given by Equation 1 and 2 and Equation 3 suggested by Panthi (2006) for estimating rock mass strength are used as a basis for the analysis below. Intact rock properties of the project cases are estimated based on lab testing carried out at the NTNU engineering geological laboratory and also by the project owner during project implementation phases (NEA 1998; NEA 2002). Tunnel convergence measured at both Kali Gandaki 'A' and Middle Marsyangdi headrace tunnels were key inputs for the uncertainty analysis. and more than 80 percent of the tunnel alignment has overburden exceeding 200 meters, which is critical in respect of tunnel squeezing.

\section{Middle Marsyangdi Headrace Tunnel}

The Middle Marsyangdi Hydroelectric Project has an installed capacity of 69 MW. The project utilizes a gross head of approximately 110 meters and a design discharge of $80 \mathrm{~m}^{3} / \mathrm{s}$ to produce the maximum installed capacity.

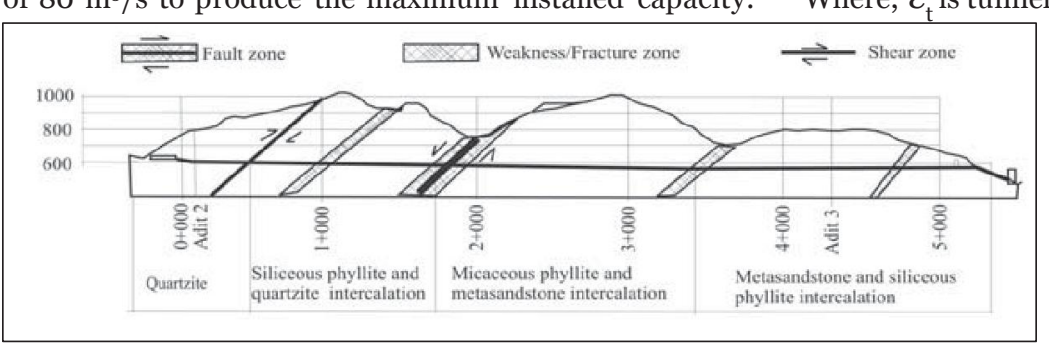

Figure 3. Profile of the Middle Marsyangdi Headrace Tunnel.

$$
\begin{aligned}
& \left.\varepsilon_{t}=\left(0.2-0.25 \times \frac{p_{i}}{\sigma_{v}}\right) \times\left[\frac{\sigma_{c m}}{\sigma_{v}}\right]^{\left(2.4 \times \frac{p_{i}}{\sigma_{v}}-2\right.}\right) \\
& \varepsilon_{t}=0.2 \times\left(\frac{\sigma_{c m}}{\sigma_{v}}\right)^{-2} \\
& \sigma_{c m}=\frac{\sigma_{c i}^{1.5}}{60}
\end{aligned}
$$

Where; $\varepsilon_{t}$ is tunnel strain in percentage, $\sigma_{v}$ is overburden stress in $\mathrm{MPa}, \sigma_{\mathrm{cm}}$ is rock mass strength in $\mathrm{MPa}$ and $\mathrm{p}_{\mathrm{i}}$ is rock support pressure in $\mathrm{MPa}$.

The tunnel strain $\left(\varepsilon_{t}\right)$ defined by Equation 1 and 2 is considered as an uncertainty that is dependable mainly on three variable input parameters; i.e. rock mass strength $\left(\sigma_{\mathrm{cm}}\right)$, overburden stress $\left(\sigma_{\mathrm{v}}\right)$ and 
rock support pressure $\left(\mathrm{p}_{\mathrm{i}}\right)$. This means that the main principle of predicting squeezing based on Hoek and Marinos (2000) approach is to define these variable input parameters. The tunnel strains (tunnel closure) is expressed in percentages and defined as:

$$
\varepsilon_{\mathrm{t}}=\frac{\delta_{\mathrm{t}}}{\mathrm{B}} \cdot 100
$$

Where, $\delta_{\mathrm{t}}$ is horizontal convergence in meters and $\mathrm{B}$ is the excavation width or diam-eter of the tunnel in meters.

Since the uncertainties encompass natural variability and randomness, the best way to quantitatively analyze these uncertainties is to use the probability density (relative density) function (pdf). The probability density function (pdf) describes the relative likelihood that a random variable may have a particular value. The selection of such mathematical distribution models should always be based on numerical calculations, experimental or field measured results and logical judgment made by observation (Panthi and Nilsen 2010).

An uncertainty analysis model as suggested by Panthi (2006) is used for further squeezing analysis and comparison. Principally, the following four step procedure is applied for assessing the tunnel squeezing using Equations 1 to 3:

1. Representative mathematical probability distribution functions (pdf) for the different input variables associated with squeezing are defined.

2. Simulation is carried out by using the software program @Risk (PA 2002).

3. Probability distribution of the uncertainty in question, in this case squeezing expressed by Equation 1 and 2, is achieved from simulation.

4. Finally the results are interpreted and compared with the actually occurred squeezing.

\section{Squeezing Analysis}

A slightly more than two kilometer long tunnel segment between chainages $1964 \mathrm{~m}$ and $4032 \mathrm{~m}$ of the Kali Gandaki
'A' headrace tunnel was used by Panthi (2006) for the uncertainty analysis of tunnel squeezing. At this section, the headrace tunnel passes through highly schistose and sheared graphitic phyllite and the rock cover (rock overburden) ranges from 425 to 620 meters (Figure 2). Since actually measured tunnel convergences (deformations) were available for this tunnel section, main emphasis was given to verify the reliability of Equation 1, 2 and 3. Based on this verification, the degree of tunnel squeezing at the Middle Marsyangdi headrace tunnel was predicted for a section between Jamitri and Khahare Khola (between chainage $2000-3400$ ) (Figure 3). At this section, the rock mass is dominated mainly by very weak, micro-folded micaceous phyllite with intercalations of meta-sandstone (Panthi and Nilsen 2007).

The estimated statistical ranges of input variables and values calculated according to Equation 1, 2 and 3 are given in Table 1 . The table highlights the minimum, maximum and mean values of input variables and the respective tunnel strain $\left(\varepsilon_{t}\right)$.

According to Panthi (2006) an exponential probability density function (pdf) is rele-vant for the inverse of overburden pressure $(1 / \gamma \mathrm{h})$. In fact, the higher the overburden $(\mathrm{h})$, the smaller the value of $1 / \gamma \mathrm{h}$, but the more likely squeezing is to occur. Similarly, the lower the overburden (h), the higher the value of $1 / \gamma \mathrm{h}$, but the less likely squeezing is to occur. This is why an exponential probability density function is considered to be the most representative distribution model for $1 / \gamma \mathrm{h}$.

Similarly, as for a laboratory tested population of intact rock strength, most of the values of rock mass strength should in general cluster towards its mean value and with certain dispersion from it, representing the standard deviation. Therefore, the normal probability density function is considered to be the most representative distribution model for rock mass strength $\left(\sigma_{\mathrm{cm}}\right)$. Similar will be the case, i.e. a normal distribution, for support pressure $\mathrm{p}_{\mathrm{i}}$.

The @Risk uncertainty analysis model was run

\begin{tabular}{|c|c|c|c|c|c|c|c|c|c|c|c|}
\hline \multirow{2}{*}{$\begin{array}{l}\text { Description } \\
\text { of input } \\
\text { variables }\end{array}$} & \multicolumn{5}{|c|}{ Kali Gandaki 'A' tunnel segment } & \multicolumn{6}{|c|}{ Middle Marsyangdi tunnel segment } \\
\hline & Min. & Max. & Mean & St.dev. & $\begin{array}{l}@ \text { Risk } \\
\text { values }\end{array}$ & Min. & Max. & Mean & St.dev. & $\begin{array}{l}@ \text { Risk } \\
\text { values }\end{array}$ & Selected pdf \\
\hline $1 / \sigma_{v}=1 / \gamma \mathrm{h}$ & 0.060 & 0.087 & 0.073 & 0.011 & 0.076 & 0.087 & 0.198 & 0.121 & 0.013 & 0.134 & Exponential \\
\hline$\sigma_{\mathrm{cm}}$ (Eq. 3) & 2.47 & 5.89 & 4.05 & 1.21 & 4.28 & 1.49 & 5.89 & 3.45 & 1.45 & 3.59 & Normal \\
\hline$p_{i}$ & 0.46 & 1.27 & 0.71 & 0.3 & 0.75 & 0.46 & 1.27 & 0.71 & 0.30 & 0.75 & Normal \\
\hline$\sigma_{\mathrm{cm}} / \gamma \mathrm{h}$ & 0.148 & 0.51 & 0.29 & & 0.34 & 0.13 & 1.17 & 0.38 & & 0.50 & \\
\hline$\varepsilon_{t}($ Eq. 1) & 7.85 & 0.54 & 1.82 & & 1.43 & 9.27 & 0.11 & 1.03 & & 0.59 & \\
\hline$\varepsilon_{\mathrm{t}}$ (Eq. 2) & 9.20 & 0.76 & 2.26 & & 1.75 & 11.87 & 0.15 & 1.36 & & 0.81 & \\
\hline
\end{tabular}

Table 1. Statistical Ranges of Input Variables for Graphitic Phyllite for Kali Gandaki 'A' and for the Schistose Phyllite at Middle Marsyangdi Headrace Tunnels (Panthi 2006; Panthi and Nilsen 2007). 

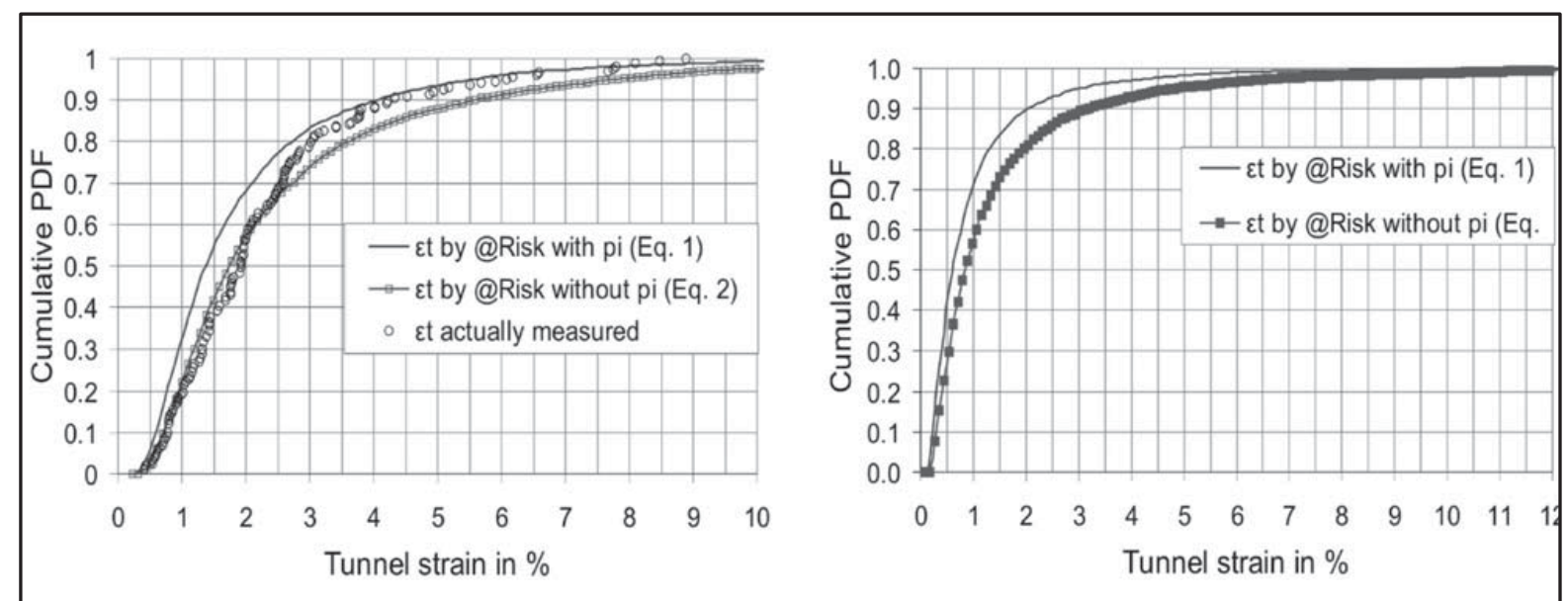

Figure 4. Cumulative Distribution of Tunnel Strains between Chainage 1964-4032 of the Kali Gandaki 'A' Headrace Tunnel (left) and Predicted Cumulative Distribution of Tunnel Strain for Chainage 2000-3400 of Middle Marsyangdi Headrace Tunnel (Panthi 2006; Panthi and Nilsen 2007).

based on the probability density functions (pdf) of each input variable as given in Table 1 . The results achieved by simulation regarding pseudorandomly distributed cumulative tunnel strain $\left(\varepsilon_{t}\right)$ based on equation 1, 2 and 3 are shown in Figure 4 (see also Table 1).

As shown in Figure 4, the cumulative probability distribution of the pseudorandomly calculated tunnel strains based on the Hoek and Marinos (2000) approach using the tool @Risk and the calculated cumulative distribution of tunnel strains based on actually measured horizontal convergence are found to be in very close agreement. This indicates that the assigned probability density functions for the input variables are realistic. As highlighted by Panthi (2006), the most important aspect of this uncertainty analysis was, of course, to verify the applicability of Equation 3 with the Hoek and Marinos (2000) approach of squeezing analysis (Equation 1 and 2).

As seen in Figure 4-left, the correlations achieved for the Kali Gandaki 'A' are considered to be quite good and a similar approach was hence used in predicting the squeezing at the Middle Marsyangdi headrace tunnel (Panthi 2006; Panthi and Nilsen 2007). Hence, a similar approach was used to predict the degree of tunnel squeezing in the tunnel segment between chainage 2,000 - 3,400 of the Marsyangdi headrace tunnel (Figure 3). The results of the uncertainty analysis are shown in Figure 4.

Based on Figure 4-right, Panthi (2006) predicted that out of the 1,400 meter long headrace tunnel between Jamitri and Khahare Khola, 70 percent of the tunnel length (approximately 980 meters) had a probability of tunnel squeezing with a magnitude of less than one percent, 25 percent (approximately 350 meters) had a probability of tunnel squeezing with a magnitude between 1 and 2.5 percent and 5 percent (approximately 70 meters) had a probability of tunnel squeezing with a magnitude exceeding 2.5 percent. The author also highlighted that due to intercalation of meta-sandstone within micaceous phyllite, a positive effect on the extent of squeezing will most likely be achieved. Therefore, the author concluded that the risk of exceeding tunnel strains with a magnitude higher than 5 percent was considered low (Panthi and Nilsen 2007; Panthi 2012).

\section{Recorded Tunnel Strains along Predicted Tunnel Segment}

During tunnel excavation, a convergence (deformation) monitoring plan was imple-mented at the Middle Marsyangdi headrace tunnel, which also experienced

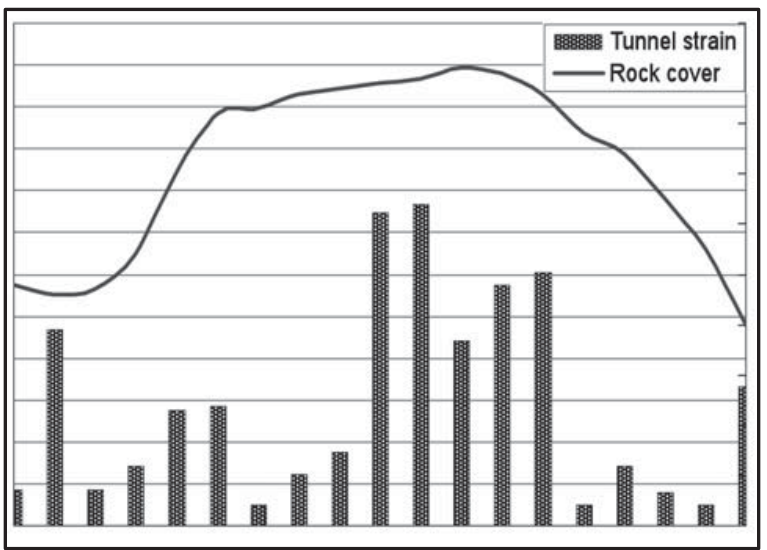

Figure 5. Tunnel Strain (Squeezing) in Percent and Rock Cover above Tunnel in Meters from Chainage 1,974 to 3,449 at the Middle Marsyangdi Headrace.

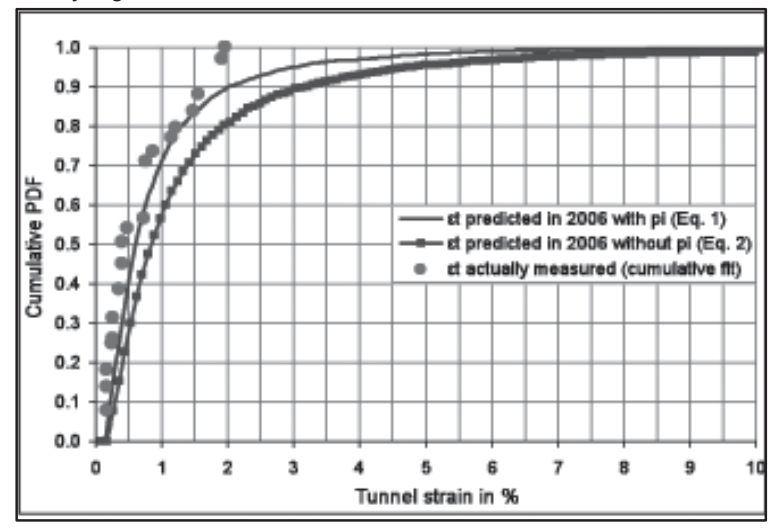

Figure 6. Cumulative Distribution of Actually Measured and Predicted Tunnel Strains between Chainage 2,000-3,400 of the Middle Marsyangdi Headrace Tunnel. 
consider-able amount of tunnel squeezing. The measured horizontal convergences between chainage 1,974 to 3,449 are converted to tunnel strains $\left(\varepsilon_{t}\right)$ using Equation 4 and the results are presented in Figure 5.

As seen in Figure 5, the magnitudes of horizontal tunnel strains vary considerably within this section of the headrace tunnel. The figure also illustrates that even within similar overburden heights there are considerable differences in the degree of tunnel squeezing. This suggests that the quality of rock mass, and in particular rock mass strength, varies greatly within short tunnel distances.

\section{Comparison between Predicted and Actual Squeezing}

The information provided by Figure 4-right was used as a basis in predicting the degree of tunnel squeezing in a tabular form (see predicted part of Table 2) by Panthi (2006). Since the actually measured squeezing results are available now, it is of great interest to compare these results with the predicted ones. This can be done by fitting the actually measured tunnel strains shown in Figure 5 within the predicted cumulative distribution of tunnel strains presented in Figure 4-right. Figure 6 is the result in this endeavor, which includes predicted cumulative distribution of tunnel strains by Panthi (2006) and the calculated cumulative distribution of tunnel strains of the actually registered (measured) ones presented in Figure 5 .

Figure 6 indicates that most of the tunnel strains actually measured fit quite well with the predicted cumulative distribution curve of the tunnel strains calculated using Equation 1, i.e. with support pressure $\left(\mathrm{p}_{\mathrm{i}}\right)$, which is in fact very logical. Because, the tunnel convergence measurement was carried out only after the scaling and application of rock support consisting of steel ribs at one meter spacing, $20-25 \mathrm{~cm}$ thick reinforced shotcrete and systematic radial bolting. The predicted and actually measured tunnel strains are shown in Table 2.

Table 2. Predicted (Panthi 2006) and Actually
Measured Squeezing Tunnel Length Based on Tunnel Data (NEA 2007) at Middle Marsyangdi Headrace Tunnel between Chainage 2000 and 3400m.

As seen in Table 2, the deviation between the predicted and actually measured tunnel length with tunnel strains below 2.5 percent is below 6 percent, which is considered to be extremely good. The same can be seen in Figure 6 with a quite good fit between the actually measured and predicted (in 2006) tunnel strains for the magnitudes of less than 2.5 percent. However, Table 2 also indicates that about a 70 meter length of this headrace tunnel segment was predicted to experience tunnel strains exceeding 2.5 percent. However, as seen in Figure 5 and 6 , no measured tunnel strains were recorded with a value exceeding this limit along this tunnel segment.

\section{Discussions}

The accuracy in predicting tunnel squeezing depends on the reliability of the estimated input variables and equations that are used for such analysis. The selection of the representative probability distribution functions (pdf), the input variables related to equations used and reliability of the equations in use for such predictions are key factors. The possible reasons for the deviation in the tunnel strain results exceeding 2.5 percent in the above uncertainty analysis may, therefore, be explained as described below:

1. Firstly, tunnel excavation is a routine work that involves mucking, scaling and application of rock support. Considerable time is already spent between excavation and completion of the support work during which instantaneous deformation already takes place in the rock mass surrounding the tunnel periphery. On the other hand, the convergence monitoring, in general, only starts after this routine work is completed.

2. Secondly, the support resistance achieved by the applied rock support consisting of steel ribs at one meter spacing, 20-25 cm thick steel reinforced shotcrete and radial bolting might have been stiff

\begin{tabular}{|c|c|c|c|c|c|c|}
\hline 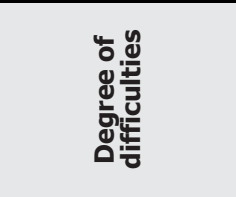 &  & 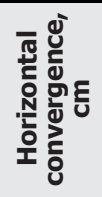 &  & 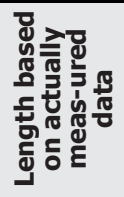 & 紊き & $\begin{array}{l}\text { Possible consequences on applied rock } \\
\text { support }\end{array}$ \\
\hline $\begin{array}{l}\text { Insignificant } \\
\text { squeezing }\end{array}$ & $<1$ & $<7$ & 980 & 1036 & 6 & No or very minor impact on aplied support \\
\hline Minor squeezing & & $1-2.5$ & & $7-16$ & & $\begin{array}{c}\text { Cracks on applied shotcrete, slight yielding on rock } \\
\text { bolts. }\end{array}$ \\
\hline Severe squeezing & & $2.5-5$ & & $16-32$ & & $\begin{array}{l}\text { Slight buckling on steel ribs, cracks on applied } \\
\text { shotcrete and yielding on rock bolts. }\end{array}$ \\
\hline $\begin{array}{l}\text { Very severe } \\
\text { squeezing }\end{array}$ & $5-10$ & & $32-64$ & - & & \\
\hline Extreme squeezing & $>10$ & & $>64$ & - & & \\
\hline
\end{tabular}

Table 2. Predicted (Panthi 2006) and Actually Measured Squeezing Tunnel Length Based on Tunnel Data (NEA 2007) at Middle Marsyangdi Headrace Tunnel between Chainage 2000 and 3400m. 
enough to limit the deformation. Unfortunately, no instrumentation was carried out to register the rock support pressure $\left(\mathrm{p}_{\mathrm{i}}\right.$ ) at the Middle Marsyangdi. Therefore, it makes verification a difficult task.

3. Thirdly, the intercalation of the relatively strong metasandstone bands within the highly schistose phyllite may have helped in achieving a slabing (arching) effect surrounding the tunnel periphery of the rock mass, which might have a positive influence for the large deformations to take place.

4. Fourthly, the uncertainty analysis tools such as @ Risk may also result in some degree of discrepancies. In particular, the lower five percent and higher five percent values of the cumulative curve may be considered as outliers due to the pseudorandom distribution.

5. Finally, the deviation may also be explained by the fact that the rock mass strength calculated by Equation 3 (Panthi 2006) and tunnel strain calculated by Equation 1 and 2 (Panthi 2012) cannot be expected to give results with hundred percent accuracy.

\section{Conclusion}

The most important aspect of this uncertainty analysis was to verify the applicability of Equation 1, 2 proposed by Hoek and Marinos (2000) and Equation 3 proposed by Panthi (2006). In addition, verification of the applicability of the suggested methodology in predicting tunnel squeezing by Panthi (2006) and the applicability of assigned probability distributions were also the key issues. The correlations achieved from both the Kali Gandaki 'A' and Middle Marsyangdi are considered to be quite good. Hence, the suggested methodology of the probabilistic approach of uncertainty analysis in predicting tunnel squeezing is a relevant tool. It is therefore, recommended to be used in the planning of tunnel projects passing through schistose and deformable rock mass.

Krishna Kanta Panthi, $P h D$, is an Associate Professor in Geological Engineering in the Department of Geology and Mineral Resources Engineering, Norwegian University of Science and Technology (NTNU), Trondheim, Norway. He has completed his Dr. Ing. degree on the 'Analysis of Engineering Uncertainties Related to Tunneling in the Himalayan Rock Mass Conditions' in
2006 from NTNU. He completed his M.Sc. in Hydropower Development in 1998 and M.Sc. in Civil Engineering in 1992. He is the author of many scientific papers related to tunneling, rock slope engineering and hydropower. He has over 15 years of experience in the design, construction and planning of tunneling and hydropower projects in the Himalaya (Nepal and India).

Corresponding address: krishna.panthi@ntnu.no

\section{References}

Panthi, K. K., 2006, Analysis of engineering geological uncertainties related to tunnelling in Himalayan rock mass conditions. PhD thesis. Department of geology and mineral resources engineering. Norwegian University of Science and Technology (NTNU), Norway.

Panthi, K. K. and B. Nilsen, 2007, Uncertainty analysis of tunnel squeezing for two tunnel cases from Nepal Himalaya. International Journal of Rock Mechanics and Mining Sciences, volume 44, pp. 67-76.

Panthi, K. K. and B. Nilsen, 2010, Uncertainty analysis for assessing leakage through water tunnels: a case from Nepal Himalaya. Rock Mechanics and Rock Engineering, vol. 43, pp. 629-639.

Panthi, K. K., 2012, Probabilistic approach in assessing tunnel squeezing - a discussion based on tunnel projects from Nepal Himalaya. Proceedings: 46th US Rock Mechanics/Geomechanics Symposium held in Chicago, IL, USA, 24-27 June 2012.

Hoek, E. and P. Marinos, 2000, Predicting tunnel squeezing problems in weak heterogeneous rock masses. Tunnels and tunnelling international, vol. 32 (11 and 12), pp. 45-51 and pp. 34-36.

Nepal Electricity Authority (NEA), 1998, Upgrading of feasibility study. Middle Marsyangdi Hydroelectric Project.

Nepal Electricity Authority (NEA), 2002, Project completion report. Volume IV-A and V-C. Geology and geotechnical. Kali Gandaki 'A' Hydroelectric Project. Syanga. Nepal.

Nepal Electricity Authority (NEA), 2007, Instrumented data records. Middle Marsyangdi hydroelectric project. Unpublished.

Palisade Corporation (PA), 2002, Guide to using @ Risk. Risk analysis and simulation add-in for Microsoft Excel. Version 4.5, 499 p.

\section{CALENDAR OF EVENTS - DRINKING WATER}

5-7 February, 2013: GEOGEN 2013: Towards Sustainable Safe Drinking Water Supply in Developing Countries- The Challenges of Geogenic Contaminants and Mitigation Measures. Location: Addis Ababa, Ethiopia. Contact Email: geogen2013@ eawag.ch. More info: http://www.eawag.ch/medien/ veranstaltungen/events/geogen2013/index_EN

9-12 October, 2013: International Conference on
Drinking Water Safety, Security and Sustainability. Location: Hangzhou, China. More info: http:// drinkingwater.zju.edu.cn/

21-24 October, 2013: 15th Canadian National Conference and 6th Policy Forum on Drinking Water. Location: Delta Grand Okanagan Hotel and Conference Center, Kelowna, BC, Canada. More info: http://www. cwwa.ca/DrinkingWaterConference_e.asp 